\title{
ESTUDO DE CASO SOBRE GESTÃO TECNOLÓGICA E COMPETITIVIDADE EM UMA OPERADORA DE TELEFONIA MÓVEL BRASILEIRA
}

\section{A CASE STUDY OF TECHNOLOGICAL MANAGEMENT AND COMPETITIVENESS IN A BRAZILIAN MOBILE TELEPHONY OPERATOR}

\author{
Maria Alice Frontini \\ Consultora, $\mathrm{MsC}$ e $\mathrm{PhD}$ \\ Universidade de São Paulo \\ Escola Politécnica \\ Departamento de Engenharia de Produção
}

Av. Prof. Almeida Prado, tr.2, n.128, Cid.Universitária, São Paulo- SP, CEP 05508-800

Tel: 3091-5363; E-mail: frontini@alum.mit.edu

Prof.Dr. Eduardo Pinheiro Gondim de Vasconcellos

Professor Titular

Universidade de São Paulo

Faculdade de Economia, Administração e Contabilidade

Departamento de Administração

Av. Prof. Luciano Gualberto, 908 Cid.Universitária, São Paulo- SP, CEP 05508-800

Telefone: (11) 3032-3897, E-mail: epgdvasc@usp.br

\author{
Prof.Dr. Fernando José Barbin Laurindo \\ Professor Associado \\ Universidade de São Paulo \\ Escola Politécnica \\ Departamento de Engenharia de Produção
}

Av. Prof. Almeida Prado, tr.2, n.128, Cid.Universitária, São Paulo- SP, CEP 05508-800

Tel: 3091-5363 r454; E-mail: fjblau@usp.br 


\begin{abstract}
RESUMO
Cada vez mais são complexas as decisões sobre investimentos em tecnologia orientados à inovação. As incertezas quanto ao benefício das inovações ligadas à convergência digital são grandes e a pressão competitiva nos setores correlatos força as empresas a adotarem a liderança tecnológica. Neste contexto, é relevante que a tecnologia seja adequadamente gerida, para sustentar a competitividade das empresas.

Este trabalho visa, através da metodologia de estudo de caso, avaliar o alinhamento entre a estratégia empresarial e a estratégia tecnológica orientada à inovação. Para tanto, trabalha com conceitos de alinhamento entre gestão estratégica e tecnológica das empresas, propõe uma abordagem e aplica-a para um caso real. As análises aqui contidas foram realizadas baseando-se em fontes secundárias sobre operadoras brasileiras de telefonia móvel e nas informações coletadas na empresa estudada, o que possibilitou verificar a aplicabilidade e coerência da abordagem proposta, ao mesmo tempo em que identifica algumas limitações das análises realizadas.
\end{abstract}

Palavras-chave: Planejamento Estratégico e Tecnológico, Avaliação da Inovação Tecnológica, Convergência Digital.

\begin{abstract}
Decisions about investments in technology aiming innovation are complex in the digital convergence. There are great uncertainties concerning benefits and significant competitive pressure to make companies to adopt a technological leadership attitude.

In this context, it is important that technology should be properly managed, in order to be source of competitive advantage.

This paper aims to evaluate, through the case study methodology, the alignment between business strategy and technological innovation strategy.

Thus, this paper encompasses concepts of strategic alignment between business and technology, which are adapted and applied in the selected case that is a very representative of the Brazilian mobile telecom market. The analyses were performed based on secondary data about Brazilian mobile telephony operators and on information gathered in the studied company, which allowed verifying the applicability and coherence of the proposed approach, and the limitations of the performed analysis.
\end{abstract}

Keywords: Technological and Strategic Planning, Technological Innovation Evaluation, Digital Convergence 


\section{INTRODUÇÃO E OBJETIVOS}

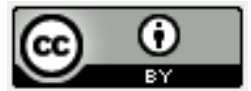

As decisões sobre investimentos em tecnologia, particularmente investimentos orientados à inovação são cada vez mais são complexas. As incertezas quanto ao real benefício das inovações tecnológicas ligadas à convergência digital (tecnologia da informação, de telecomunicações e mídia) são grandes. Adicionalmente, a pressão competitiva nos setores correlatos força as empresas a adotarem uma atitude de liderança tecnológica (TRITLE et al., 2000).

Dentro deste contexto de elevada incerteza e competitividade, ainda é mais relevante que a tecnologia seja adequadamente gerida, para que esta seja um dos elementos diferenciadores e sustentadores da competitividade das empresas. O sucesso da gestão tecnológica está cada vez mais engendrado às dimensões estratégicas, mercadológicas e organizacionais das empresas (MARCOVITCH, 1991).

Este trabalho visa analisar o alinhamento entre a gestão estratégica e gestão tecnológica das empresas. Julga-se de extrema relevância que este aprendizado seja conceituado, estruturado e analisado para que as experiências do passado auxiliem as decisões futuras quanto à inovação tecnológica, e não permitam que os erros sejam recorrentes frente a futuras ondas tecnológicas.

Para este fim, a abordagem metodológica adotada para a presente pesquisa exploratória foi a de estudo de caso. Os critérios para selecionar a empresa para este estudo de caso foram: uma empresa atuando no mercado brasileiro, a existência de um processo de planejamento estratégico e a busca de inovações tecnológicas como fonte de vantagem competitiva.

A empresa selecionada, aqui denominada "Operadora A", que opera no ramo de telefonia móvel em âmbito local e mundial, investe muito em tecnologia de ponta no mercado brasileiro, possui experiência mundial em aplicá-la e a utiliza para sustentar sua liderança em mercados europeus. Em termos de inovação tecnológica, a empresa é pressionada por seus acionistas e por seus gestores para desenvolver uma oferta inovadora e para alavancar a experiência mundial do grupo.

O referencial teórico deste trabalho aborda os conceitos básicos de gestão estratégica das empresas, alinhamento entre estratégia empresarial e tecnológica. Os conceitos apresentados são estruturados e adaptados, propondo uma abordagem para a avaliação. Finalmente, esta abordagem é aplicada no estudo de caso, em um contexto bastante atual na telefonia móvel brasileira. 


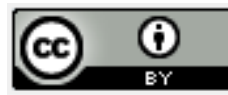

Assim, na empresa estudada é avaliado o alinhamento entre a estratégia empresarial e a estratégia tecnológica orientada à inovação, a fim de diagnosticar quais as lacunas existentes no plano tecnológico desta empresa que devem ser supridas para assegurar a competitividade a médio e longo prazo.

As análises aqui contidas foram realizadas pelos autores baseadas informações setoriais obtidas de fontes secundárias e em informações coletadas na empresa em estudo. Apesar das informações do estudo de caso terem sido obtidas somente junto à alta gestão da empresa, a riqueza do estudo está em verificar a aplicabilidade e coerência da abordagem proposta, ao mesmo tempo em que identifica algumas limitações das análises realizadas.

\section{ESTRATÉGIA E A COMPETITIVIDADE EMPRESARIAL}

Pode-se sintetizar, de acordo com Serra, Torres e Torres (2002) que a elaboração do planejamento estratégico baseia-se na definição dos objetivos estratégicos e na escolha de ações que levarão a empresa a atingir os resultados planejados.

A definição de objetivos estratégicos é uma maneira de se materializar a visão e a missão da empresa, pois é aquilo que a empresa almeja alcançar concretamente no curto e longo prazo, atendendo aos interesses de todos os que direta ou indiretamente participam na empresa, i.e., os stakeholders. No curto e médio prazo os objetivos são na sua maioria materializados em resultado financeiros, enquanto no longo prazo em resultados que asseguram a longevidade da empresa.

Como em qualquer outra realidade, para se sair de um estado e atingir outro existem várias alternativas. O mesmo se dá com as empresas ao definirem um objetivo estratégico, i.e., várias alternativas de ações (estratégias) existem para se alcançar o objetivo. No entanto, para se identificar as alternativas e fazer uma escolha adequada, é fundamental o entendimento do contexto competitivo onde a empresa está inserida (CARVALHO; LAURINDO, 2007).

A dinâmica competitiva do setor econômico pode ser compreendida através das seguintes análises propostas por Porter (1991): as cinco forças estruturais atuantes no setor; a avaliação dos pontos de força e de fraqueza, e identificação das ameaças e oportunidades derivadas de mudanças passíveis na conjuntura competitiva. 
Segundo Porter (1991), a intensidade da competitividade em um setor econômico pode ser analisada a partir de cinco forças competitivas: novos entrantes, poder de barganha dos clientes e fornecedores, ameaça de produtos substitutos e rivalidade dos competidores. $\mathrm{O}$ potencial de rentabilidade de um setor é função da intensidade dessas forças competitivas. Quanto mais competitivo o setor, menor será o retorno dos investimentos, tendendo ao patamar mínimo de um mercado livre perfeito.

A empresa deve identificar seus pontos de forças e fraquezas perante cada força competitiva, bem como identificar as ameaças e oportunidades derivadas de mudanças passíveis de ocorrer na conjuntura competitiva ou até mesmo mudanças provocadas pela empresa. Conseqüentemente, a análise SWOT (Strengths, Weakness, Opportunities, Threats) é outra ferramenta analítica básica para a formulação estratégica de uma empresa (PORTER, 1991).

O planejamento estratégico de uma empresa envolve a definição de seu posicionamento nos negócios, com o objetivo de alavancar as características que a distinguem da concorrência (CARVALHO; LAURINDO, 2007) . Há três tipos de estratégias genéricas, segundo Porter (1991), em função da vantagem competitiva almejada e do mercado atendido. Uma empresa pode competir baseada em baixos custos ou na diferenciação dos produtos e serviços que ofereça, e também optando por atender todo o mercado ou enfocar em um segmento específico.

A vantagem competitiva baseada em custo pode ser alcançada a partir de melhorias contínuas nos processos da empresa em busca de melhoria na eficiência, ou através da inovação das atividades para atingir redução significativa nos patamares de custos. A vantagem competitiva orientada à diferenciação baseia-se em uma oferta de produto e/ou serviço superior em relação aos atributos valorizados pelo cliente, possibilitando à empresa cobrar preços superiores. Finalmente, a vantagem competitiva em atender um nicho de mercado (enfoque) baseia-se no fato de que a empresa deve possuir as competências e capacitações para atender o nicho. 


\section{ESTRATÉGIA TECNOLÓGICA ORIENTADA À INOVAÇÃO E A COMPETITIVIDADE EMPRESARIAL}

A estratégia tecnológica desempenha um papel relevante na competitividade das empresas, particularmente na inovação, seja esta de ruptura ou de sustentação. Marcovitch (1991) destaca a relação entre inovação e crescimento das vendas e participação no mercado (market share) das empresas, concluindo que a lucratividade das empresas é determinada pela integração e alinhamento entre a estratégia empresarial e a estratégia tecnológica. O autor evidencia que não basta a uma empresa possuir os elementos condicionantes à inovação, também não basta formular uma estratégia e um plano de tecnológico; o fator crítico de sucesso está em como a empresa aplica este plano capturando o valor de seu diferencial competitivo.

Fundamentalmente, para o mesmo autor, há três dimensões que condicionam uma empresa a adotar e capturar benefícios concretos de uma competitividade tecnológica: ambiente externo, a empresa e o corpo dirigente (ou a alta gestão).

No ambiente externo às empresas, a estabilidade macroeconômica aliada à baixa volatilidade do risco país induz o empresariado a agir com enfoque no médio e longo prazo, usualmente compatível com as decisões orientadas à inovação. Também são determinantes os programas governamentais de fomento aos investimentos e a inserção de mecanismos para a difusão tecnológica, a existência do capital de risco, a facilidade de criação de novas empresas e a existência de recursos humanos capacitados.

No ambiente interno às empresas, seu posicionamento frente ao mercado e a sua atitude perante a tecnologia são determinantes. Mercados com elevada rivalidade levam à inovação, pois a diferenciação contínua é fator determinante da competitividade empresarial. Também fundamentais são: a capacidade da empresa em prospectar tecnologia, sua habilidade em absorver e aplicar as novas tecnologias frente às demandas de mercado e aos objetivos empresariais.

Quanto ao perfil da alta gestão, é fator crítico a cultura que ela insere na organização através de uma postura direcionada à inovação, critérios de decisão orientados a incorrer riscos, prospectar continuamente alternativas tecnológicas e uma visão orientada aos negócios. 


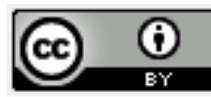

Existem basicamente dois tipos de inovação com a qual as empresas se deparam. $\mathrm{O}$ primeiro tipo, denominada inovação de sustentação (sustained innovation) por Christensen \& Overdorf (2000), é orientada à melhoria dos produtos e serviços, segundo os atributos de performance tecnológica valorizada pelos clientes mais rentáveis e mais exigentes. O segundo tipo, denominada inovação de ruptura (“disruptive innovation”), é orientada a novos atributos de valor, viabilizando a introdução de novos negócios ou mercados.

Segundo a pesquisa realizada Charitou e Markides (2003), existem basicamente cinco movimentos estratégicos que as empresas dominantes adotam perante uma inovação de ruptura:

- Focar no negócio tradicional e fortalecer suas vantagens competitivas.

- Ignorar o novo entrante, pois não faz parte do mesmo negócio.

- Contra-atacar, levando à auto-canibalização.

- Adotar e conviver com os dois “jogos”, gerindo o risco de conviver com negócios conflitantes.

- Abraçar a inovação e disseminá-la, lidando com os trade-offs intrínsecos.

Finalmente, semelhante à formulação da estratégia empresarial, a formulação da estratégia tecnológica orientada à inovação engloba a definição dos objetivos estratégicos e a escolha de ações que levarão a empresa a atingir os resultados planejados. Assim como na estratégia empresarial, a escolha da melhor alternativa para a empresa perseguir baseia-se na avaliação da situação da empresa (competências, forças e fraquezas, etc.), e no diagnóstico do ambiente externo em relação às tecnologias emergentes e à evolução da tecnologia dominada pela empresa. A estratégia formulada pela empresa é traduzida em um plano tecnológico, que estabelece os objetivos e os meios para atingi-los.

\section{ABORDAGEM ADOTADA PARA AVALIAÇÃO DO CASO}

Para atingir o objetivo deste trabalho, i.e., diagnosticar o alinhamento entre a estratégia empresarial e a estratégia tecnológica orientada à inovação, utilizar-se-á uma abordagem adaptada das idéias propostas por Marcovitch (1991) e de Vasconcellos e Andrade (1996).

A idéia central é identificar o plano tecnológico orientado à inovação da empresa avaliada e analisar seu alinhamento à estratégia empresarial. Para tal, utilizar-se-ão os 
conceitos anteriormente descritos relativos à estratégia e competitividade empresarial, estratégia empresarial orientada à inovação e estratégia tecnológica competitiva. Quatro passos são executados para se avaliar o alinhamento entre a estratégia empresarial e tecnológica, i.e.:

- $\quad$ análise do ambiente competitivo,

- $\quad$ entendimento da estratégia empresarial,

- $\quad$ identificação da estratégia em inovação tecnológica,

- $\quad$ avaliação do alinhamento entre o plano tecnológico e as diretrizes estratégicas.

A metodologia adotada para este artigo foi a de estudo de caso (MIGUEL, 2007; YIN, 1994). As informações foram coletadas através de entrevistas semi-estruturadas e complementadas por dados setoriais obtidos de fontes secundárias.

\section{ESTUDO DE CASO}

Um dos setores econômicos brasileiros quer tem sido mais afetado pela convergência digital é a telefonia móvel. Neste setor a inovação tecnológica caracteriza-se tanto por ser de sustentação como de ruptura. No primeiro caso, o enfoque da inovação está em melhorar o desempenho das operações para lidar com mercados em massa e otimizar seus resultados; enquanto no segundo caso, a inovação dos serviços de telefonia (VAS - "Value Added Services") tem procurado buscar novos atributos de valor para seus clientes, para se diferenciar da concorrência (Stienstra et al. 2004; Lal et al. , 2004). Particularmente, esses serviços são viabilizados por dois elementos tecnológicos: a rede de telefonia, e a tecnologia de informação (TI).

A operadora selecionada para o estudo (denominada doravante Operadora A) é uma operadora relevante na telefonia móvel brasileira, possui um planejamento estratégico formal e sua marca explora a inovação tecnológica como um diferencial competitivo.

\section{O Ambiente Competitivo da Telefonia Móvel Brasileira}

O mercado de telefonia móvel brasileira caracteriza-se por elevada concentração em torno de 4 players e acirrada competição a nível nacional. Com a privatização do setor em 1998, eram previstos 3-4 players por área de concessão. Com a desregulamentação do 


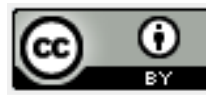

mercado desde 2002, iniciou-se um movimento de consolidação nacional, apresentando hoje 4 grandes operadoras: Vivo, Claro, TIM, Oi. (Teletime-Atlas Brasileiro de Telecomunicações 2004).

A evidência de elevada competitividade no mercado brasileiro pode ser observada através da existência de pelo menos três competidores nos mercados mais rentáveis, i.e., aproximadamente 800 municípios, totalizando 65 milhões de habitantes e o maior índice de poder de consumo (49\%), conforme Teletime-Atlas Brasileiro de Telecomunicações (2004). ). O marco da competitividade se deu com a introdução da tecnologia GSM (Global System for Mobile) no cenário nacional, através de massivos investimentos realizados pela OI e TIM. Acompanhando a onda tecnológica as operadoras que trabalham com TDMA (Time Division Multiple Access) estão sobrepondo suas redes para a tecnologia GSM (caso da Claro) ou migrando suas bases TDMA para a tecnologia CDMA (Code Division Multiple Access), como é o caso da Vivo). Conseqüentemente há uma tendência no Brasil de dominância de duas tecnologias digitais, i.e., GSM e CDMA.

Estima-se uma penetração de 32,2\% para 2004 no mercado brasileiro, e um crescimento anual superior a $32 \%$ a.a. Apesar da baixa penetração da telefonia móvel brasileira frente a mercados desenvolvidos (p.ex. penetração média européia 80\%), as classes alvo de ofertas inovadoras possuem uma elevada penetração no Brasil (classe $\mathrm{A}=$ $92 \%$, Classe $\mathrm{B}=51 \%)$.

Os chamados serviços de valor adicionado (VAS) são ainda basicamente insignificantes (aproximadamente 3\% das receitas), mas desempenham um papel relevante na manutenção da receita média por usuário (ARPU - Average Revenue Per User) que no entanto tende a cair ao longo dos anos. Basicamente se categoriza VAS (Value Added Services) em dois tipos: tradicional e inovativo (termos usados pelas operadoras). O VAS tradicional engloba soluções tecnológicas baseadas na troca de texto (SMS - Short Message Service), enquanto que o VAS inovativo faz uso de outras features tecnológicas mais complexas, tais como MMS (Multimedia Messaging System), WAP (Wireless Application Protocol), etc..

A liderança do mercado nacional tanto em termos de base de usuários como de receita cabe a VIVO. Com investimentos e presença nos mercados de maior rentabilidade, o posicionamento competitivo da VIVO é de diferenciação baseada na elevada cobertura e qualidade de sua rede, reforçado por uma imagem de credibilidade e solidez, cobrando preços superiores em função deste posicionamento (Quadro 1). 
A segunda posição do mercado é disputada acirradamente por Claro e TIM, com posicionamentos bastante diversos. A Claro com um posicionamento de baixo custo enquanto a TIM também tenta posicionar-se com uma estratégia de diferenciação baseada na inovação e oferta diferenciada. Finalmente, a OI posiciona-se em segmentos específicos com uma abordagem diferenciada.

\begin{tabular}{|c|c|c|c|c|}
\hline & VIVO & CLARO & $T / M$ & OI \\
\hline $\begin{array}{l}\text { Estratégia } \\
\text { percebida }\end{array}$ & $\begin{array}{l}\text { - Crescimento seletivo com } \\
\text { foco em rentabilidade }\end{array}$ & $\begin{array}{l}\text { Expansão agressiva } \\
\text { (base e rede),alavan-cando } \\
\text { sobre a sólida posção } \\
\text { financeira }\end{array}$ & $\begin{array}{l}\text { Ser o 2 player no Brasil, } \\
\text { garantindo o retorno ao } \\
\text { acionista }\end{array}$ & $\begin{array}{l}\text { Expansão agressiva de base } \\
\text { pouco focada no retorno do } \\
\text { investimento }\end{array}$ \\
\hline Imagem & $\begin{array}{l}\text { - Provedora de cobertura e } \\
\text { - qualidade de rede } \\
\text { Solidez, tradģão e confiabilidade }\end{array}$ & $\begin{array}{l}\text { - Popular } \\
\text { - Preços baixos } \\
\text { - Ofertas competitivas } \\
\text { - Piora na cobertura }\end{array}$ & $\begin{array}{l}\text { - Operadora nacional } \\
\text { - Confiabilidade e foça } \\
\text { - Tecnologicalleader } \\
\text { - Promoçôes inovadoras e } \\
\text { diferenciadas }\end{array}$ & $\begin{array}{l}\text { - Jovem/dinâmica } \\
\text { - Inovadora (handsetse } \\
\text { propaganda atraente) } \\
\text { - Agressiva comercialmente }\end{array}$ \\
\hline Alvo & $\begin{array}{l}\text { - Heavyuserse mercado } \\
\text { corporativo }\end{array}$ & - Mediume lowusers & $\begin{array}{l}\text { Heavye mediumusers } \\
\text { mercado corporativo }\end{array}$ & $\begin{array}{l}\text { - Jovens } \\
\text { - Mediume low users }\end{array}$ \\
\hline Metas & $\begin{array}{l}\text { - Posicionamento do } 1 \text { XRTT } \\
\text { como } 3 G \\
\text { - Desenvolvimento dooverlay } \\
\text { CDMA focado emrenta } \\
\text { bilidade(RS, CO e NO) } \\
\text { - Retenção por ações focadas } \\
\text { - Desenvolvimento de ofertas } \\
\text { fixo/móvel } \\
\text { - Integração das operã̧̧es }\end{array}$ & $\begin{array}{l}\text { - Desenvolvimento dasstartups } \\
\text { - Realizacão do overlay GSM } \\
\text { (principalmente em SP) } \\
\text { - Roll-out GSM agressivo } \\
\text { - Migração da base atual de } \\
\text { - TDMA para GSM } \\
\text { - Consolidæ̧ão da marca } \\
\text { - Integração da BCP (SP/NE) }\end{array}$ & $\begin{array}{l}\text { - Desenvolvimento dœOverlay } \\
\text { GSM e inovæãa } \\
\text { - Integração das operz̧ões } \\
\text { - Retercão da base nasáreas } \\
\text { incumbents } \\
\text { - Ataque à base da concorrência } \\
\text { nas áreas de start up }\end{array}$ & $\begin{array}{l}\text { - Crescimento da base } \\
\text { - Desenvolvimento de produtos } \\
\text { fixo/móvel } \\
\text { - Estabilização da cobertura } \\
\text { comercial } \\
\text { - Manutenção do foco no varejo } \\
\text { (promoçôes e subśdios) }\end{array}$ \\
\hline
\end{tabular}

Quadro 1 - Análise de posicionamento estratégico (elaborado pelos autores)

A análise SWOT dos competidores indica que a maior ameaça da VIVO está no ataque a sua base feita pelos concorrentes, no entanto o crescimento de sua base anunciado em julho de 2004 indica que esta ameaça é praticamente insignificante. Para a Claro, sua maior fraqueza esta na consolidação das operações adquiridas, no entanto essas fraquezas são largamente compensadas pela experiência de seu acionista (grupo Telmex) e pela sinergia com a Embratel. A TIM desponta no cenário como a única operadora "pura móvel", sua força esta na marca e sua maior ameaça é a Claro. A Oi não tem tanta experiência em GSM como a TIM e Claro, e não possui uma atuação nacional, o que pode representar fraquezas no que tange economias de escala, sua maior força esta na agressividade comercial.

A análise das cinco forças estruturais do setor aponta que as operadoras de telefonia móvel possuem uma situação relativamente confortável, com exceção da própria rivalidade. 
- Barreiras a novos entrantes: A principal barreira de entrada nesse mercado é a elevada necessidade de capital, apenas em 2003 e 2004, foram investidos aproximadamente R \$4 bilhões pelas operadoras móveis. As práticas de interconexão entre as operadoras dificultam ainda mais a entrada de novos competidores no mercado.

- Pressão de produtos substitutos: Como formas alternativas de prestação do serviço de telefonia local, podem-se citar a telefonia fixa, principalmente com sua nova oferta de prépago e a telefonia IP para transmissão de dados (sinais) e os serviços de longa distância e fixa no médio-longo prazo. Quanto ao atributo mobilidade, um produto substituto é o satélite, mas os preços elevados desta tecnologia praticamente não competem com a telefonia móvel.

- Poder de barganha dos compradores: possuem um poder de barganha relativamente baixo. Apesar da possibilidade de trocar de operadora, a ausência da portabilidade numérica impõe uma barreira à troca pelo consumidor.

- Poder de barganha dos fornecedores: os fornecedores de equipamentos e terminais são poucos (Siemens, Nokia, Motorola, Ericson), as demandas concentradas e os contratos mundiais de longo prazo, tornando o poder de barganha dos fornecedores reduzido.

- Rivalidade entre os concorrentes: este mercado é extremamente competitivo quanto à disputa do $2^{\circ}$. lugar. O principal foco de competição no mercado de telecomunicações são os clientes corporativos e os clientes com perfil de consumo de alto valor.

Conforme indicado por Porter, em mercados altamente competitivos a rentabilidade tende ao patamar mínimo, conseqüentemente, a aquisição de clientes de alto valor e a diferenciação da oferta através da inovação são fatores de competitividade chave para a manutenção das margens e para a remuneração do elevado capital investido.

\section{Estratégia Empresarial da Operadora A}

A Operadora A possui uma estratégia genérica orientada a todo o mercado, com destaque à diferenciação e inovação de sua oferta através dos serviços de valor adicionado. Conseqüentemente, a inovação tecnológica é um dos elementos centrais de sua estratégia empresarial. 
Sua marca é forte e é reconhecida pela inovação tecnológica, solidez e credibilidade da empresa. A receita média de seus clientes atuais (ARPU) são superiores a da concorrência, conseqüência direta da estratégia focada em clientes de alto valor.

Os objetivos estratégicos da Operadora A são: diferenciação, inovação e qualidade de sua cobertura e serviços ao cliente.

A Operadora A almeja adquirir os segmentos mais rentáveis do mercado, isto é, corporate e consumer heavy user. Dentro deste contexto, os serviços de valor adicionado são fontes relevantes de receita e de competitividade futura. Para esses segmentos, a Operadora A deliberadamente define uma proposição de valor diferenciada, viabilizada pela inovação tecnológica, como elemento crítico para a sua competitividade.

Sinteticamente, as diretrizes e os objetivos de competitividade da Operadora A são baseados em: oferta inovadora, orientação ao cliente, cobertura, presença nacional, marca forte, defesa do ARPU e a otimização tanto do OPEX (operative expenditures), do CAPEX (capital expenditures) como dos processos internos.

\section{Inovação Tecnológica da Operadora A}

Dentre os tipos de movimentos estratégicos que as empresas dominantes adotam perante a inovação de ruptura na visão de Charitou e Markides (2003), a Operadora A caracteriza-se por abraçar a inovação e disseminá-la. A Operadora A investe nas novas gerações tecnológicas e busca disseminá-las mundialmente, acelerando seu "time-to-market".

Em linhas gerais a estratégia tecnológica de inovação da Operadora A pode ser sintetizada por:

- Assegurar a disponibilização contínua de serviços de valor adicionado ao cliente

- Utilizar as soluções já existentes no grupo, para sair na frente da concorrência, garantir a qualidade do serviço e reduzir os investimentos e custos operacionais necessários

Fundamentalmente, a Operadora A disponibiliza e gerencia a infra-estrutura básica de rede para obter a liderança em inovação no mercado brasileiro, trabalhando os atributos tecnológicos valorizados pelo cliente: cobertura, serviços de qualidade, confiabilidade e disponibilidade da rede. 
Especificamente para as soluções da TI, a empresa reutiliza os serviços de valor adicionado (VAS) desenvolvidos pelo grupo, customizando-os às necessidades do mercado nacional. Basicamente as seguintes tecnologias da informação são as habilitadoras dos serviços VAS: SMS (short message), envio e recebimento de emails, download de arquivos de dados e de multimídia.

Genericamente, as diretrizes de inovação em serviços tecnológicos da Operadora A endereçam quatro atributos para os clientes de alto valor:

- Utilidade: o cliente se comunica melhor, de forma simples e rápida através de SMS, etc.

- Emoções: o cliente compartilha emoções e sentimentos, através de envio de fotos, vídeos, etc.

- Ser inovador: o cliente quer experimentar o novo, estar na ponta de qualquer serviço

- Produtividade móvel: conectividade e mobilidade em qualquer lugar e em qualquer momento

Observando-se o cruzamento entre as tecnologias de rede e de TI, conclui-se que há coerência entre as diretrizes da Rede e da TI na da infra-estrutura tecnológica disponibilizada para viabilizar os serviços de inovação almejados pela empresa.

\section{Consistência entre o Plano Tecnológico e as Diretrizes Estratégicas}

Baseando-se na abordagem de Vasconcellos e Andrade (1996), para avaliar a consistência entre o plano tecnológico às diretrizes estratégicas da Operadora A, avalia-se a contribuição dos projetos de inovação tecnológica e as respectivas tecnologias aos objetivos estratégicos.

No Quadro 2 apresenta-se a lista de projetos VAS, i.e., o código dos projetos e a respectiva tecnologia habilitadora embutida em cada projeto, ordenados de acordo com sua contribuição à estratégia da empresa. Primeiramente, elenca-se a lista de fatores de competitividade sob a ótica da Operadora A e sob a ótica do cliente, indicando os atributos de valor para o cliente dos serviços de telefonia móvel. O objetivo de classificar sob as duas óticas é fazer uma priorização dos projetos que considere ambas as dimensões, os objetivos estratégicos e a percepção do cliente, já que em um mercado tão competitivo como o de 
telefonia móvel, a percepção do cliente é decisiva na decisão da compra e manutenção do relacionamento com a empresa. Atribuem-se em seguida pesos relativos de 1 a 3 aos fatores avaliados em cada uma das dimensões. Por exemplo, na dimensão competitividade julga-se mais relevante a contribuição de um projeto à oferta inovadora (peso=3) do que ao impacto no opex (peso=1), na dimensão atributos de valor para o cliente, julga-se o fator utilidade $($ peso=3) mais valorizado pelo cliente do que o fator emoção (peso =1).

Posteriormente, classificaram-se os projetos em alto, médio e baixo em termos de sua contribuição aos fatores analisados em cada uma das dimensões (competitividade e atributos de valor para o cliente), atribuindo-se notas de 1 a 3 (1= baixa, 3 = alta). Normaliza-se a nota final ponderada até o máximo de 10. Finalmente, o ranking dos projetos indica sua prioridade à Operadora $\mathrm{A}$, enquanto que o cruzamento das dimensões competitividade e atributo de valor fornece uma visão da consistência dos projetos à estratégia empresarial (Quadro 2). 


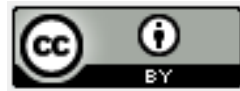

Nota-se que há uma discrepância em alguns projetos tecnológicos que não trabalham adequadamente os atributos de valor do cliente (p.ex. C29, CB5, C25.). Estes utilizam tecnologia de ponta, requerem elevado investimento e apresentam o risco de não cumprirem seu papel frente à estratégia empresarial. Seu escopo e abordagem poderiam ser revistos. Outros projetos poderiam ser incorporados aos prioritários, pois apesar de não contribuírem
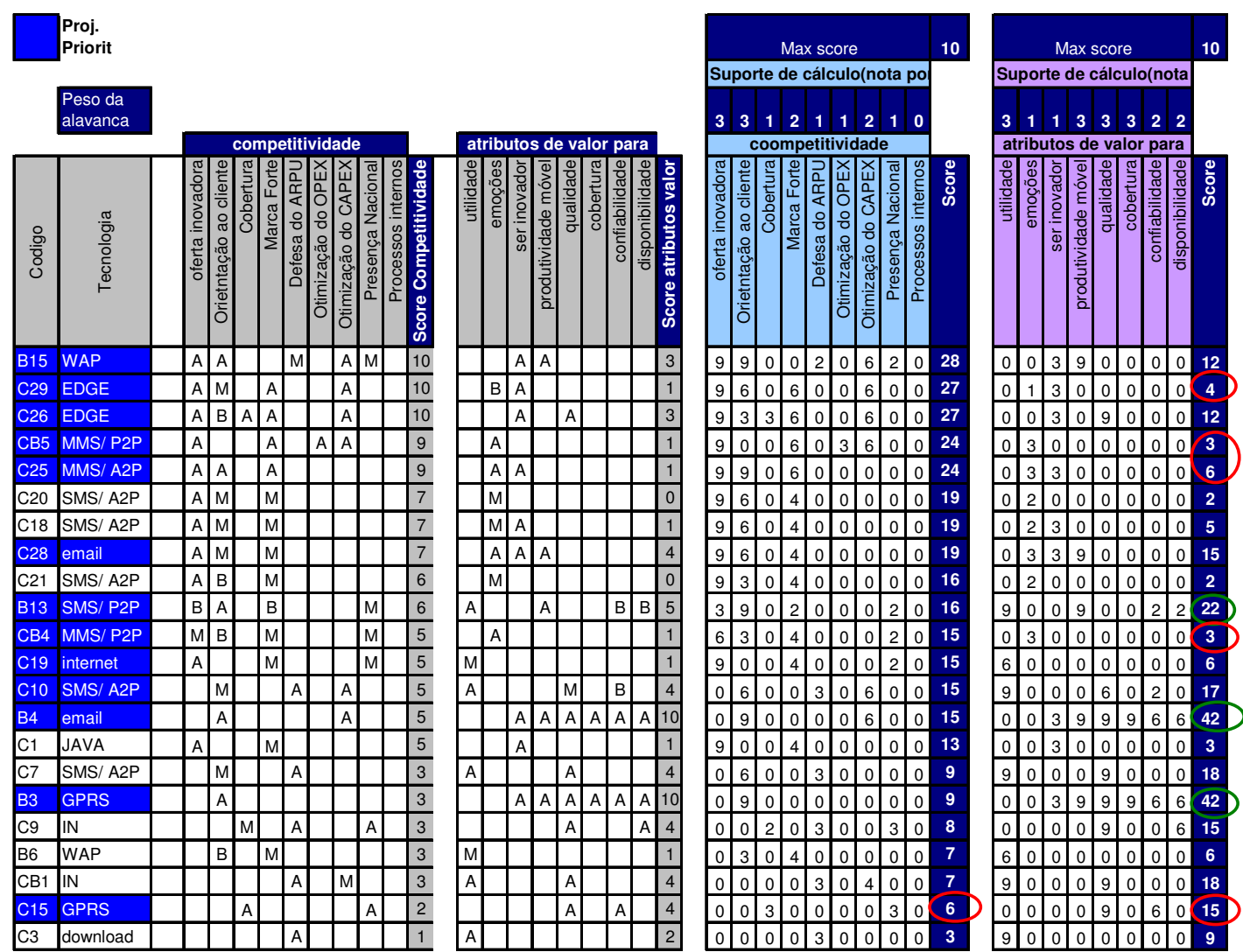

diretamente para a competitividade empresarial, trazem uma percepção diferenciada de inovação ao mercado (ex. B3, B4, B13.).

Quadro 2 - Projetos tecnológicos prioritários à Operadora A

A partir da pontuação dos projetos é possível identificar o alinhamento das tecnologias à estratégia empresarial. Utiliza-se a média da nota de contribuição da tecnologia para indicar sua relevância e localizá-la nos quadrantes. Por sua vez, a quantidade de projetos que faz uso da tecnologia é usada para apontar a participação da tecnologia no plano tecnológico e construir a circunferência relativa a cada projeto (Figura 1).

Positivamente, na sua maioria, as tecnologias estratégicas da Operadora A estão alinhadas às estratégias empresariais da empresa. Este diagnóstico advém da quantidade de tecnologias posicionadas nos quadrantes à direita ("leste') da figura 1. 
De um lado, há um conjunto de tecnologias de ponta que contribuem significativamente para a competitividade da empresa e para sua percepção de inovação frente ao mercado (quadrante "Nordeste"). Também estas tecnologias são aquelas que viabilizam uma quantidade elevada de projetos da Operadora A, demonstrando um alinhamento entre as tecnologias disponibilizadas pela empresa e seus objetivos estratégicos.

Em contrapartida, há um outro conjunto de tecnologias que contribuem significativamente para os atributos de competitividade da empresa e nem tanto para os atributos de valor do cliente (quadrante "Sudeste"). São tecnologias consideradas chave pela Operadora A em termos potenciais e que poderiam ser mais bem trabalhadas para efetivamente extrair o valor do cliente e realizar a vantagem competitiva planejada.

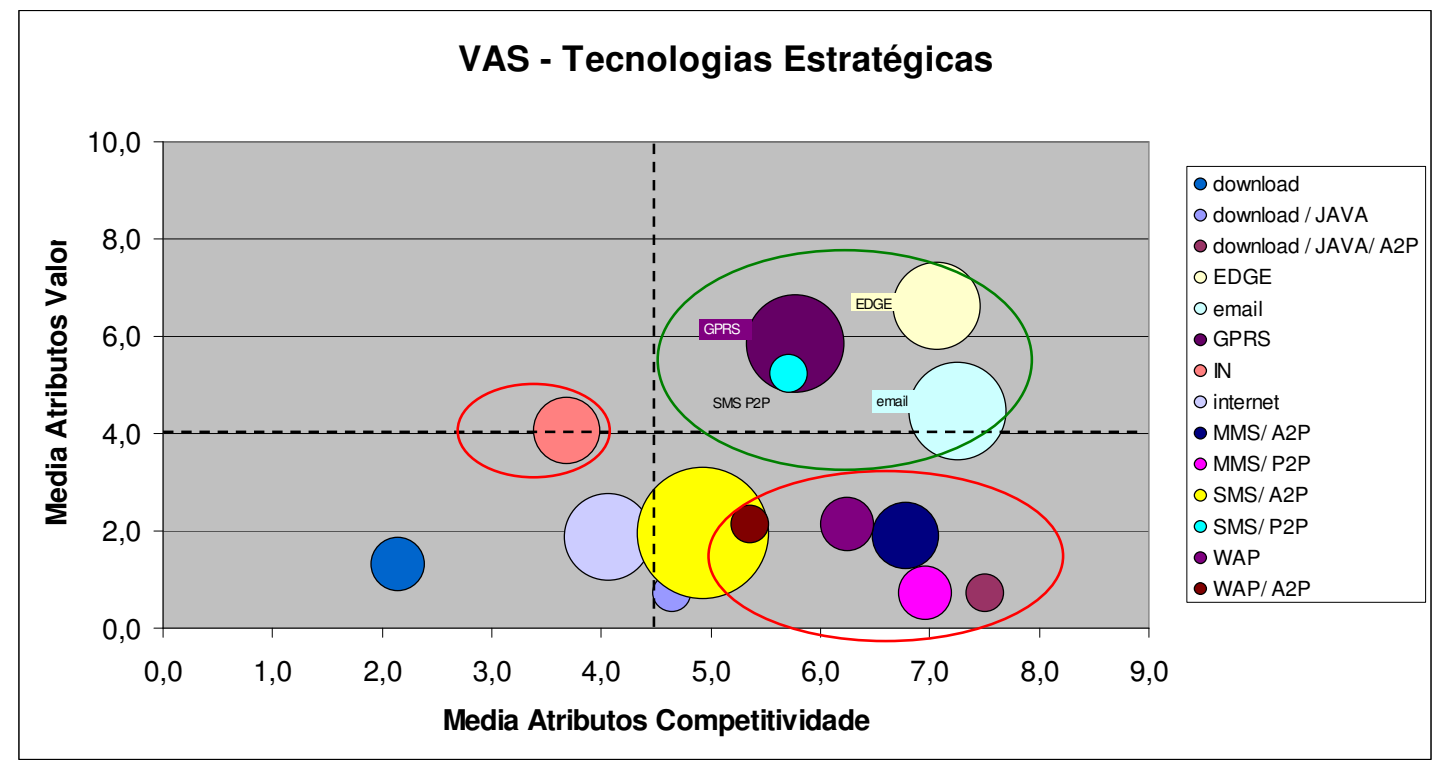

Figura 1 - Tecnologias Estratégicas da Operadora A (Elaborada pelos autores)

Finalmente, pode-se concluir que há uma elevada consistência entre o plano tecnológico de inovação da Operadora A e suas diretrizes estratégicas, em termos de projetos prioritários e das tecnologias viabilizadoras dos objetivos estratégicos. Portanto, com base no caso analisado, conclui-se que a Operadora $A$ possui uma gestão tecnológica orientada à inovação alinhada à estratégia empresarial. 


\section{CONCLUSÃO}

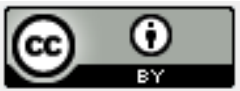

Este trabalho avaliou o alinhamento entre a estratégia empresarial e a estratégia tecnológica de uma operadora de telefonia móvel, onde a inovação desempenha um papel relevante frente à competitividade e ao contexto de convergência digital. Mostrou o quão necessário é entender o ambiente competitivo e o posicionamento e os objetivos estratégicos da empresa para se avaliar o alinhamento entre a estratégia empresarial e tecnológica.

A partir de um método simples de pontuação frente aos objetivos de competitividade e de inovação tecnológica é possível avaliar o alinhamento do plano tecnológico (projetos e tecnologias) à estratégia empresarial.

Através deste estudo também foi possível perceber que a avaliação da estratégia tecnológica nem sempre é diretamente percebida. Particularmente neste caso, foi necessário entender os serviços e produtos de inovação da empresa para identificar as tecnologias habilitadoras e, então, diagnosticar as prioridades da Operadora À em suas inovações tecnológicas de ruptura.

Finalmente, a partir das duas visões criadas, isto é, a visão empresarial e a tecnológica da "Operadora A" foi possível avaliar o alinhamento entre ambas.

A “Operadora A' possui uma gestão tecnológica orientada a inovação bastante alinhada a sua estratégia empresarial. Porém, a análise revela dois pontos nos quais haveria necessidade de alguns ajustes, que devem ser considerados por outras organizações em um contexto similar em termos de estratégia e de gestão tecnológica e da inovação:

- Uma melhor priorização de seus esforços, selecionando os projetos que mais contribuem com seus objetivos estratégicos para alavancar os investimentos feitos em tecnologias de ponta;

- Estar alerta para efetuar revisão de alguns projetos que aparentam uma incoerência entre diferencial competitivo e o valor percebido pelo cliente final.

Cabe lembrar que em um ambiente globalizado, a avaliação da gestão tecnológica deve transcender as fronteiras brasileiras. Neste sentido, a "Operadora A" possui processos orientados à transferência tecnológica de VAS, evidenciado através da forma de trabalho junto à matriz que disponibiliza uma quantidade de soluções técnicas, mas nem sempre comercializadas. Em contrapartida, a "Operadora A" possui uma deficiência em traduzir os 
produtos tecnológicos disponíveis em uma oferta inovadora percebida / valorizada por seu cliente final, ou seja, em viabilizar uma oferta atrativa à demanda local, dentro das características específicas do mercado.

Cabe salientar que este estudo possui limitações. Poderia avaliar mais detalhadamente o estágio de evolução tecnológica da Operadora A para subsidiar o plano tecnológico com competências e capacitações necessárias. Adicionalmente, poderia entender o comportamento estratégico da Operadora $A$ frente à inovação e as implicações deste comportamento em seu plano tecnológico.

Tais pontos poderão ser contemplados em futuros estudos, que tratem da estratégia em empresas que lidam com o mercado de telecomunicações, com a inovação e com a convergência digital.

\section{REFERÊNCIAS BIBLIOGRÁFICAS}

CARVALHO, M.M.; LAURINDO, F.J.B. Estratégia Competitiva: dos conceitos à implementação. São Paulo, Editora Atlas, 2007.

CHARITOU, C.D.; MARKIDES, C.C. Responses to Disruptive Strategic Innovation. MIT Sloan Management Review, Vol. Winter, p.55-63, 2003.

CHRISTENSEN, C.M.; OVERDORF M. Meeting the challenge of disruptive change. Harvard Business Review, p.66-76, Mar/Apr, 2000.

CHRISTENSEN, C.M.; RAYNOR, M., VELINDEN, M. Skate to where the Money will be, Harvard Business Review, v79,n10, p.72-81, November, 2001.

LAL, D.; PITT, D.; STRACHAN, P. Strategic Change in UK Telecommunications: Empirical Evidence European Management Journal Vol. 22, No. 1, pp. 99-109, 2004.

MARCOVITCH, J. Tecnologia e competitividade. Revista de Administração, Vol.26, n.2, p 12-21, 1991.

MARKIDES, C. What is strategy and how do you know if you have one? Business Strategy Review, V.15,i2, p.5-12, Summer 2004.

MIGUEL, P. A. C. Estudo de caso na engenharia de produção: estruturação e recomendações para sua condução. Revista Produção, v. 17, n. 1, p. 216-229, 2007.

O’REILlY, C.A.; TUSHMAN, M.L. The ambidestrous Organization. Harvard Business Review, Vol. Apr, p74-8, 2004.

PORTER, M.E.; MILLAR, V. How Information gives you competitive Advantage. Harvard Business Review, Vol. May-Jun, p146-160, 1985. 
PORTER, Michael E. Estratégia Competitiva. Rio de Janeiro, Campus. 1991.

SERRA, F.A.R.; TORRES, M.C.S.; TORRES, A.P. (2002) Administração estratégica: Conceitos Roteiro Prático e Casos. Reichmann \& Affonso Editores, cap. 7, p.95-113.

STIENSTRA, M.; BAAIJ, M.; VAN DEN BOSCH, F.; VOLBERDA, H. Renewal of Europe's Largest Telecom Operators (1992-2001): From Herd Behaviour Towards Strategic Choice? European Management Journal Vol. 22, No. 3, pp. 273-280, 2004.

TELETIME. Atlas Brasileiro de Telecomunicações. São Paulo. 2004.

TRITLE, G.L; SCRIVEN, E.F.V.; FUSFELD, A.R. Resolving Uncertainty in R\&D Portfolios. Industrial Research Institute, nov-dec, p47-55, 2000.

VASCONCELLOS E.; DE ANDRADE V.L Planejamento estratégico da Tecnologia na Companhia Vale do Rio Doce. XIX Simpósio de Gestão da Inovação Tecnológica, São Paulo, 22 -25.out, 1996.

YIN, ROBERT K. "Case study research: design and methods", Applied Social Research Methods Series, Sage, EUA, 1994. 